\title{
Modeling Urban Hydrology: A Comparison of New Urbanist and Traditional Neighborhood Design Surface Runoff
}

\author{
Christopher Andrew Day ${ }^{1}$, Keith Allen Bremer ${ }^{2}$ \\ ${ }^{1}$ Department of Geography and Geosciences, University of Louisville, Louisville, USA \\ ${ }^{2}$ Department of Geography, Texas State University-San Marcos, San Marcos, USA \\ Email: a.day@louisville.edu
}

Received April 30, 2013; revised May 31, 2013; accepted June 28, 2013

Copyright (c) 2013 Christopher Andrew Day, Keith Allen Bremer. This is an open access article distributed under the Creative Commons Attribution License, which permits unrestricted use, distribution, and reproduction in any medium, provided the original work is properly cited.

\begin{abstract}
Urban development generally leads to an increase in impervious cover resulting in a greater volume of surface runoff following storm activity. However, the type of urban development in place strongly controls the degree of impervious cover generated. Traditional neighborhood designs focus on a medium-to-low urban density spread over larger areas, while new urbanist neighborhood designs incorporate more diversity by increasing urban density across smaller areas. The purpose of this study is to model and compare the potential surface runoff for two urban neighborhoods in Austin, Texas-Circle C Ranch, a traditional neighborhood design, and Mueller, a new urbanist development for a 10-year 24-hour storm scenario. Potential surface runoff was calculated by layering various geospatial datasets representing the physical characteristics of both study sites within the Watershed Modeling System (WMS) to configure the HEC-HMS runoff model. Results initially imply that the higher density new urbanist neighborhood significantly increases total and peak storm runoff compared to the traditional neighborhood. However, a greater number of residential units are available at Mueller over the same area as Circle C Ranch. When taking this into account the increased potential surface runoff is negated at the new urbanist site. Although new urbanist neighborhoods will usually contain more residential units than traditional developments when compared at the same scale, the higher urban density associated with these neighborhoods demand the development of more effective stormwater retention systems to cope with a potential increase in surface runoff.
\end{abstract}

Keywords: Urban Hydrology; New Urbanism; Runoff Modeling; Land Use

\section{Introduction}

Urban development affects the amount of potential surface runoff generated during storms by changing the amount of impervious cover across the landscape [1-3]. In addition to increasing surface runoff, urban development also modifies the volume of groundwater recharge, lowers water tables, increases peak discharge, and decreases base flow during drier periods [4,5]. These modifications depend on the type of urban development in place.

New urbanism is a type of sustainable development that is designed to reduce automobile use, increase walking and cycling, and increase the diversity of land uses while incorporating traditional and new practices of planning at all scales [6]. Moreover, new urbanism is a type of low impact development (LID) that contains elements such as cluster development and bio-retention. LID can mitigate problems associated with storm water runoff by increasing resilience and utilizing best management practices [7,8]. Traditional neighborhood development (TND) is limited to the neighborhood scale and incorporates traditional planning practices such as large lot and single family zoning [9]. TND are not considered as LID unless further steps have been taken to implement specific LID features. New urbanism is touted as a more environmentally sustainable development than TND, which will typically contain greater amounts of impervious cover [10].

While research implies that LID does often reduce total stormwater runoff and increase the runoff lag time when compared to TND [11-13], more research needs to be carried out which compare neighborhoods of similar 
size and scale in order to make further accurate assessments of LID and their impact on stormwater runoff. Several obstacles pertinent to stormwater runoff have been noted concerning LID planning. Many current zoning and regulatory statutes can hinder the implementation of LID concepts and philosophies [14]. These features include minimum street width for public services, concrete curbs and gutters, the absence of runoff collection ponds due to public health concerns, and other elements that may not fit into the visually pleasing aesthetic design [14]. As a result, a comparison of three urban neighborhoods ranging from high-to-low density actually found that the medium density neighborhood displayed the longest peak runoff lag times due to more effective usage of stormwater retention systems [15].

An increase in geospatial and modeling capability has increased the opportunity of analyzing urban development impacts on stormwater runoff in recent years. Remote sensing data coupled with geographic information science (GIS) systems and runoff modeling software have been used more frequently to study the interaction between rainfall events and urban surfaces leading to runoff [16-18]. The purpose of this research is to utilize these techniques to model and compare the potential surface runoff for two similar-sized new urbanist and traditional neighborhoods in Austin, Texas.

\section{Study Area}

The study area includes two neighborhoods, one new urbanist, and one traditionally developed neighborhood in Austin, Texas (Figure 1). Austin-Mueller (Mueller) is a new urbanist neighborhood located in north-central Austin approximately three miles from downtown Austin on the site of the city's old Robert Mueller airport. Mueller is the most recent master-planned community in Austin that focuses on new urbanism as a vehicle for sustainability including a mixture of home types, sizes, and price ranges. Circle $\mathrm{C}$ Ranch is a traditional neighborhood development that originated in the late 1980s. The neighborhood contains mostly single-family homes that are situated on medium to large lots with traditional planning practices in place [19].

Regarding physical characteristics that may impact stormwater runoff, Austin receives, on average, $870 \mathrm{~mm}$ precipitation annually [20]. The majority of this total occurs in the months of April and May when violent storms develop from Pacific cold fronts moving rapidly across the south-central Texas region, resulting in severe flooding [21]. Another important factor concerning runoff is the soil which heavily controls the amount of infiltration-to-surface-runoff ratio during storm events. Soils may be classified into one of four hydrologic groups (A, $\mathrm{B}, \mathrm{C}, \mathrm{D})$ that reflect their drainage capability. Group A soils are characterized by high infiltration rates to give low runoff potential following precipitation, while group D soils have low infiltration rates to increase runoff potential [22]. Soil coverage across both sites is typical of the south-central Texas region.

Mueller is dominated by the Lewisville and Altoga series soils which range from well-to-moderately drained silty-clay soils underlain by fractured chalk or limestone, classified in the B-C soil hydrologic groups. Smaller instances of the Houston Black and Patrick soil series are also present at these sites classified into the moderately-to-poorly drained B-D soil hydrologic grouping. At Circle C Ranch, the Tarrant soil series dominates as a stony-clay type soil (hydrologic group C) with the moderately well-drained ( $C$ group) Speck series present to the south and west of the site [22].

\section{Methods}

The methodology workflow incorporates a series of geospatial data sources and techniques in order to calculate potential surface runoff at both study areas (Figure 2). Land use/cover data were obtained for both sites from $1 \mathrm{~m}$ resolution Digital Orthophoto Quarter Quad (DOQQ) images from 2010. In order to directly compare the runoff generated between the two sites, the larger Circle $\mathrm{C}$

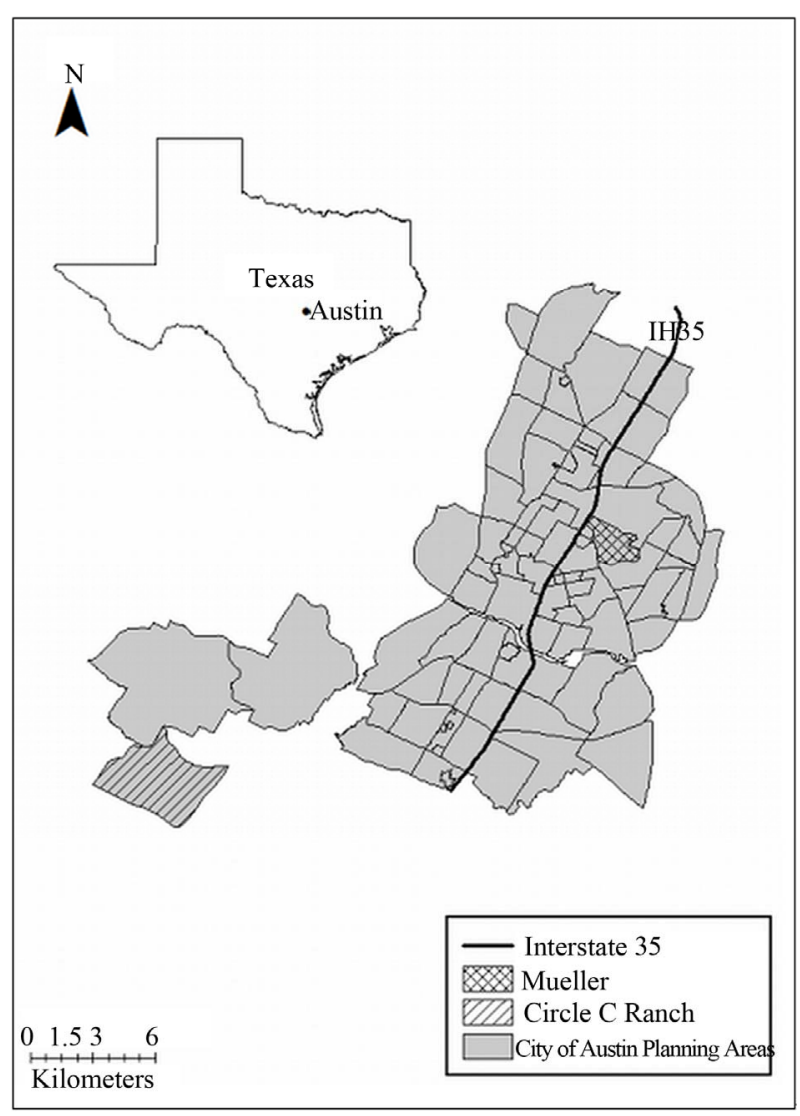

Figure 1. Study areas within Austin, Texas. 


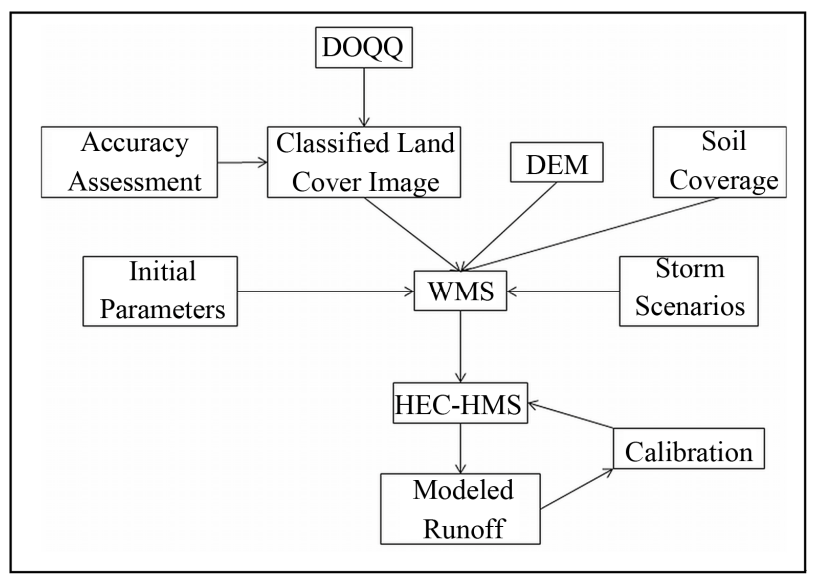

Figure 2. Methodology workflow.

Ranch site was trimmed down to match the area of Mueller, using road boundaries within the sub-division as the new boundaries for Circle $\mathrm{C}$ Ranch. This gave two images covering an equal area of $0.7 \mathrm{~km}^{2}$ with the Mueller site containing 751 residential units and Circle C Ranch 511.

The imagery was initially loaded in ArcMap before performing a supervised classification technique using the maximum likelihood algorithm. Following a visual inspection of the images, four land cover classes were identified as urban/impervious, forest, grass, and surface water (Figure 3). The classification accuracy was verified by rechecking the classified images with the original imagery. The classified images were then loaded into the Watershed Modeling System (WMS) software and combined with a digital elevation model (DEM) to calculate slope and hydraulic length (the longest flow path across each site, L) for both sites. Finally, soil coverages, containing the soil hydrologic groups for the soils at both sites, from the State Soil Geographic Database (STATSGO) were loaded into the model in order to calculate infiltration losses during storm activity, similar to previous research techniques [23] (Figure 4).

Surface runoff was calculated using the HEC-HMS model for a 10-year 24 hour storm scenario based on the surface and soil hydrologic group cover for each site. The HEC-HMS model was originally developed by the US Army Corps of Engineers (US ACE) as a lumpedparameter model, capable of routing surface flow into a series of drainage basins towards an outlet [23,24]. Various methods are available within HEC-HMS to determine runoff versus infiltration. The Soil Conservation Service (SCS) method was chosen for this study based on its success at modeling surface runoff in other urban runoff studies $[18,25,26]$, and the availability of the necessary physical data at both study sites in Austin. It is also ideally suited for modeling drainage areas of less than 2000 acres $\left(\sim 8 \mathrm{~km}^{2}\right)$ [27].

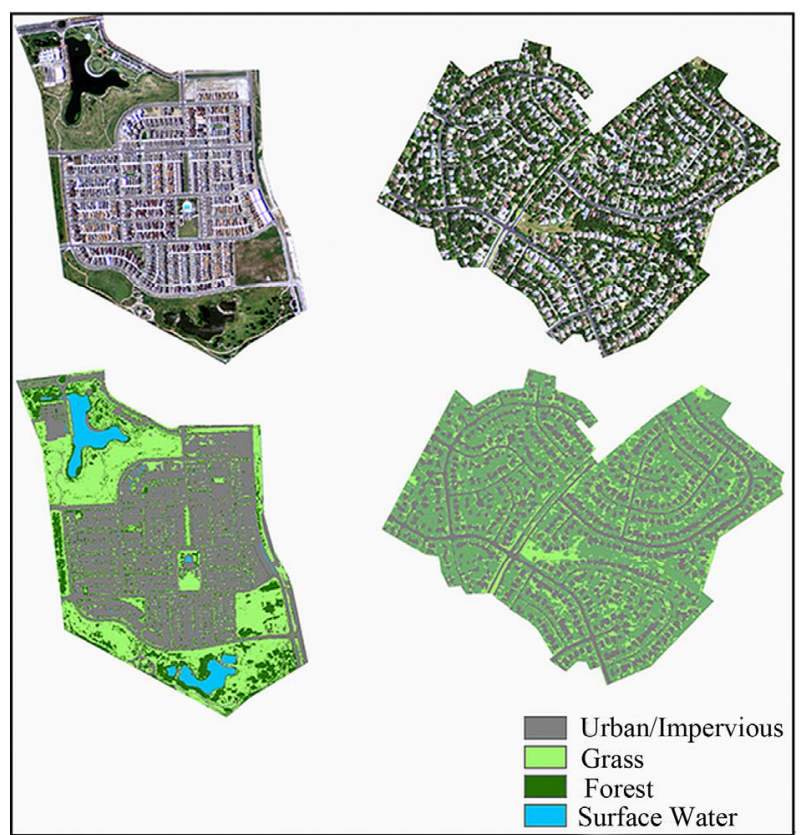

Figure 3. Landcover classification from DOQQ imagery for Mueller (left) and Circle C Ranch (right).

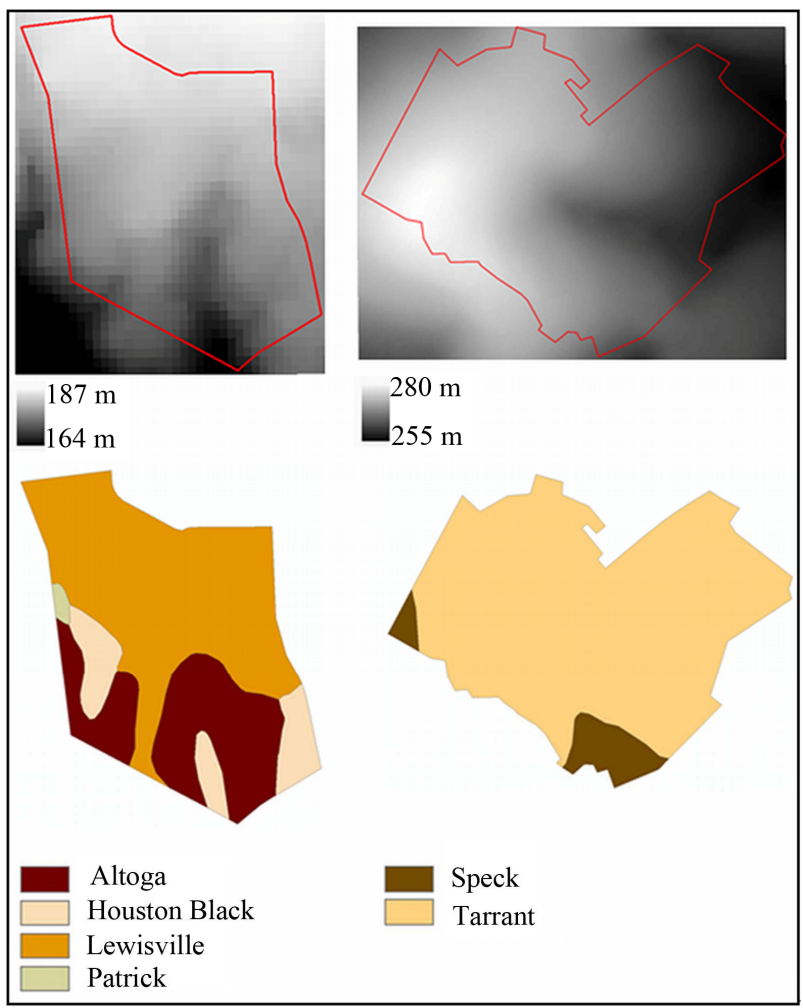

Figure 4. DEM and soil coverage for Mueller (left) and Circle C Ranch (right).

The SCS method calculates initial precipitation losses (the initial abstraction) and ultimately the volume of water available for surface runoff based on soil permeability and land cover by prescribing a predetermined 
"curve number" to each surface and soil hydrologic group cover (Equations (1) and (2)).

$$
Q=\frac{(P-I a)^{2}}{P-I a+S}
$$

$Q=$ runoff depth;

$P=$ 24-hour storm precipitation depth;

$I a=$ initial abstraction (0.2S);

$S=$ infiltration/retention losses (Equation (2)).

$$
S=\left(\frac{1000}{C N}\right)-10
$$

$C N=$ curve number for areal soil and land cover.

Higher curve numbers result from land cover and soil hydrologic groups that allow decreased infiltration, resulting in a greater volume of water made available for surface runoff. By overlaying the classified land cover data with the soil hydrologic group coverage data, a composite curve number could be generated for each site (Equation (3)) [24].

$$
C N_{\text {comp }}=\frac{\sum A_{i} C N_{i}}{\sum A_{i}}
$$

$C N_{\text {comp }}=$ composite curve number;

$A_{i}=$ drainage area of each area with uniform land and soil coverage;

$C N_{i}=$ curve number of each $A_{i}$.

The curve numbers used in Equations (2) and (3) for soil hydrologic groups and various land cover surfaces are given in Table 1.

Runoff volumes were then generated to produce hydrographs which determined the peak runoff in cubic meters per second (cms) and lag time between peak precipitation and runoff at each site. The 24-hour storm precipitation depth in equation 1 was taken from a 10-year 24 hour storm scenario for the Austin area based on the availability of local historical hydrological data for model calibration later (Table 2). Within the WMS modeling software the SCS method initially estimates basin lag time using the physical basin parameters in Equation (4), (Table 3):

$$
T_{\text {lag }}=L^{0.8} \frac{(S+1)^{0.7}}{1900 \sqrt{Y}}
$$

$T_{\text {lag }}=$ basin lag time;

$L=$ hydraulic length;

$S=$ infiltration/retention losses (Equation (2));

$Y=$ mean slope.

Calibration of the HEC-HMS model is normally achieved by comparing the modeled runoff with observed runoff obtained from a US Geological Survey streamgauge at the outlet of the modeled catchment site $[23,29]$. This was not directly possible as neither site
Table 1. Example runoff curve numbers for various land covers by soil hydrologic group [27].

\begin{tabular}{ccccc}
\hline Land Cover & \multicolumn{4}{c}{ Soil Hydrologic Group } \\
\hline & A & B & C & D \\
\hline Impervious Surfaces & 98 & 98 & 98 & 98 \\
Woods/Forest & 30 & 55 & 70 & 77 \\
Grass & 39 & 61 & 74 & 80 \\
Surface Water & 0 & 0 & 0 & 0 \\
\hline
\end{tabular}

Table 2. Approximate precipitation depths for a 10-year 24hour storm in the Austin area [28].

\begin{tabular}{cc}
\hline Time period & Precipitation depth $(\mathrm{mm})$ \\
\hline 15 min & 35.6 \\
1 hour & 68.6 \\
2 hours & 86.4 \\
3 hours & 94.0 \\
6 hours & 109.2 \\
12 hours & 121.9 \\
24 hours & 152.4 \\
\hline
\end{tabular}

Table 3. SCS model parameters generated by WMS.

\begin{tabular}{ccccc}
\hline Site & $\begin{array}{c}\text { Hydraulic } \\
\text { length, } L(\mathrm{~m})^{\mathrm{a}}\end{array}$ & $\begin{array}{c}\text { Infiltration } \\
\text { losses, } S\end{array}$ & $\begin{array}{c}\text { Slope, } \\
Y(\%)\end{array}$ & $\begin{array}{c}\text { Basin lag } \\
\text { time, } T_{\text {lag }} \\
(\mathrm{hr})\end{array}$ \\
\hline $\begin{array}{c}\text { Mueller } \\
\text { Circle C } \\
\text { Ranch }\end{array}$ & 994 & 1.6 & 1.8 & 0.5 \\
\hline
\end{tabular}

${ }^{a}$ Although meters are given, the equation requires $L$ input in feet.

contained an active stream gauge for model comparison located at the site outlets. To account for this, calibration of the runoff model took place by comparing the peak flow generated from a 10-year 24-hour storm with the observed peak flow from the nearest active stream gauge located approximately $2.4 \mathrm{~km}$ downstream from the Mueller site (Boggy Creek USGS\# 08158035). In this case the model ran using the initial conditions calculated by HECHMS from the physical site data, before adjusting the key parameter, initial abstraction, to match the proportional observed peak runoff generated at Boggy Creek. This took into account the larger catchment area of the Boggy Creek gauge location. Initial peak runoff was overestimated, and subsequent lag times underestimated, as a result of low initial abstraction parameter values generated by the model. This was corrected by increasing the initial abstraction value until the peak runoff value at Mueller proportionally matched the value at the Boggy Creek site, similar to the approach adopted by previous urban runoff modeling research 
[23,29]. Adjustment of the initial abstraction value for Circle C Ranch followed based on the lower CN value for that site (Table 4).

\section{Results}

The Mueller site contained a much greater proportion of urban/impervious cover, totaling 50\% compared to the Circle C Ranch coverage of 36\% (Figure 3, Table 5). The impervious area of the Mueller neighborhood is also clustered around a central area, surrounded by non-impervious surfaces, which typifies new urbanist developments.

The Circle C Ranch site displays a more uniform spread of all surfaces, with impervious surfaces distributed across the entire site. While Mueller does display $17 \%$ more grass coverage, the majority of the Circle $\mathrm{C}$ Ranch site is covered in forest, totaling 51\% compared to Mueller's 16\%. Mueller also includes 4\% surface water coverage in the form of two ponds located to the south and northwest of the site.

Regarding runoff, initially the two hydrographs produced by the model appear similar, but closer inspection reveals three key differences between Mueller and Circle $\mathrm{C}$ Ranch in response to the 10-year storm scenario (Figure 5). Firstly, the peak runoff increased by 64\% from $0.99 \mathrm{cms}$ at Circle C Ranch to $1.55 \mathrm{~cm}$ at the Mueller site. Secondly, the storm lag time displayed a lower value by 31 minutes at Mueller, which equated to a 59\% decrease in time from Circle C Ranch storm response. Lastly, the runoff coefficient (proportion of rainfall to runoff), increased by $5.9 \%$ at Mueller, again highlighting that a greater proportion of rainfall during the storm becomes surface runoff at this location. The results suggest that the new urbanist site at Mueller actually generates the greater volume of stormwater runoff $\left(42,000 \mathrm{~m}^{3}\right.$ vs. 35,700 $\mathrm{m}^{3}$ at Circle C Ranch). Furthermore, with both

Table 4. Curve numbers and initial abstraction values used in model.

\begin{tabular}{cccc}
\hline Site & $\begin{array}{c}\text { Default Initial } \\
\text { Abstraction (Ia) }\end{array}$ & $\begin{array}{c}\text { Calibrated Initial } \\
\text { Abstraction (Ia) }\end{array}$ & Curve Number \\
\hline Mueller & 0.2 & 0.26 & 86 \\
Circle C Ranch & 0.2 & 0.32 & 78 \\
\hline
\end{tabular}

Table 5. Proportion of surface cover at Circle $C$ Ranch and Mueller sites.

\begin{tabular}{ccc}
\hline Surface cover & Circle C Ranch & Mueller \\
\hline Impervious & $36 \%$ & $50 \%$ \\
Forest/Woods & $51 \%$ & $16 \%$ \\
Grass & $13 \%$ & $30 \%$ \\
Water & $0 \%$ & $4 \%$ \\
\hline
\end{tabular}

sites displaying similar physical properties in terms of area, relief, hydraulic length and soil hydrologic group characteristics, the greater extent of impervious surface coverage compared to the traditional site at Circle C Ranch is chiefly responsible for this.

However, it must be addressed that new urbanist developments focus on clustered development practices that have a higher density of residential development than a traditional urban development practice over a similar area. In this case Mueller contains 751 residential units compared to Circle C Ranch's 511, a total difference of 240 units over the $0.7 \mathrm{~km}^{2}$ area. Taking this into account Circle C Ranch would theoretically generate a greater volume of runoff at $69,863 \mathrm{~m}^{3}$ per 1000 units vs. $55,925 \mathrm{~m}^{3}$ per 1000 units at Mueller, a difference of just under $14,000 \mathrm{~m}^{3}$. As a result Circle C Ranch and other similar traditional urban developments, taken as a whole, will likely generate a greater volume of surface runoff than their new urbanist counterparts in terms of their total footprint on the landscape.

Of further note are the landscaped retention systems in place at the Mueller site which are designed to limit the effects of stormwater runoff, practices that are often not included across traditional developments. Bio-retention ponds are key features of new urbanist developments which aim to capture and store excess runoff following storm events. Mueller has two such ponds in place, to the north and south which have been aesthetically landscaped into the development blueprint. The DEM datasets used in this study do not capture any of these largescale landscaping changes implemented at the Mueller site, assuming that the majority of stormwater runoff will follow the original topography and drainage patterns. However the purpose of this paper was to investigate the potential surface runoff generated from this kind of development in comparison to a traditional neighborhood. The fact that new urbanist sites will often cluster their development in a bid to reduce the overall footprint of the site means that without these kinds of retention systems in place a greater volume of runoff could potentially be generated and lag times reduced following storm events as seen in this study.

\section{Conclusions}

A modeling framework has been developed to analyze the impacts of urban neighborhood design on storm runoff for the city of Austin, Texas. By layering a series of datasets that represent the physical landscape (land cover, soil, and relief) within the Watershed Modeling System (WMS) the HEC-HMS runoff model has generated peak runoff and storm lag times for a new urbanist and traditional neighborhood. The results imply that when directly comparing these types of urban design on a similar scale, the new urbanist neighborhood has the propensity to 


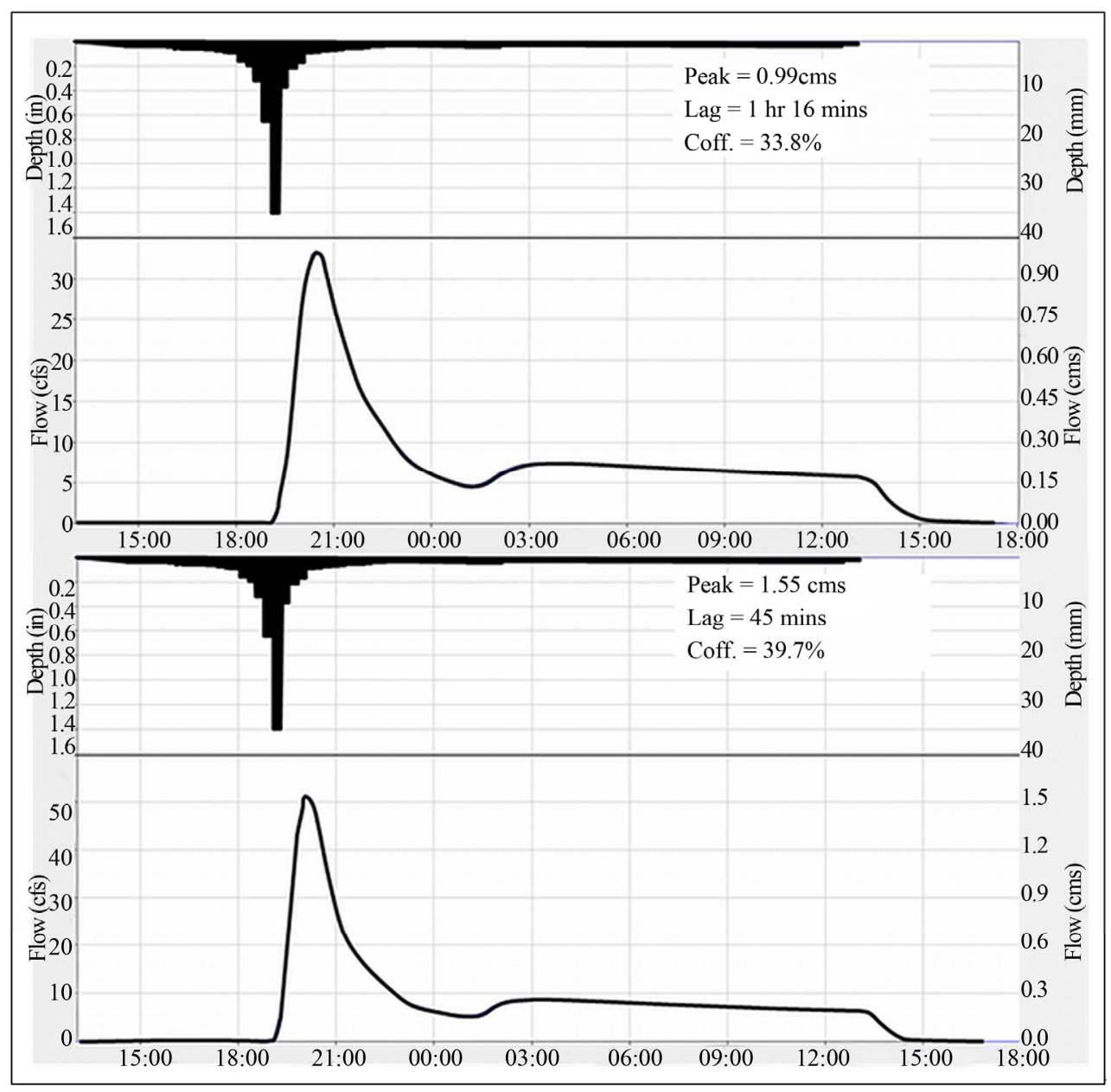

Figure 5. Modeled runoff hydrographs for Circle C Ranch (top) and Mueller (bottom).

generate larger peak flows and shorter lag times as a function of the high density urban footprint associated with this type of neighborhood. Consequently it is imperative that flood retention or reduction measures are included in these neighborhood designs in order to mitigate the impacts of potential flooding both within and surrounding these new urbanist neighborhoods. Furthermore, while new urbanist neighborhoods have LID elements designed within them to reduce runoff and pollutants at a larger scale these results suggest more research is needed to determine how well, at the smaller scale, these elements work with other neighborhood designs and to what level they reduce or increase pollutant runoff.

The methodology employed in this research demonstrates the potential of combining and manipulating a series of datasets within GIS and modeling software to ascertain the potential surface runoff generated within urban areas at the sub-drainage basin scale. However further research should also be conducted that compares potential runoff output from infiltration abstraction methods other than the SCS method as employed in this research. Also with the increase in development of new urbanist neighborhoods within US cities, similar research may be conducted that compares the potential runoff between these neighborhoods. Their non-traditional development and design often makes them unique from one another and thus could generate significantly different runoff outputs from similar storm scenarios.

\section{REFERENCES}

[1] D. B. Booth, D. Hartley and R. Jackson, "Forest Cover, Impervious-Surface Area, and the Mitigation of Stormwater Impacts," Journal of the American Water Resources Association, Vol. 38, No. 2, 2002, pp. 835-845. doi:10.1111/j.1752-1688.2002.tb01000.x

[2] L. B. Leopold, "Hydrology for Urban Planning-A Guidebook on the Hydrological Effects of Urban Land Use," US Geological Survey, Washington DC, 1968.

[3] C. J. Walsh, A. H. Roy, J. W. Feminella, P. D. Cottinghan, P. M. Groffman and R. P. Morgan, "The Urban Stream Syndrome: Current Knowledge and the Search for a Cure," Journal of the North American Benthological Society, Vol. 24, No. 3, 2005, pp. 706-723. 
doi:10.1899/04-020.1

[4] K. Gilroy and R. McCuen "Spatio-Temporal Effects of Low Impact Development Practices,” Journal of Hydrology, Vol. 367, No. 3-4, 2009, pp. 228-236.

doi:10.1016/j.jhydrol.2009.01.008

[5] P. M. Groffman, N. J. Boulware, W. C. Zipperer, R. V. Pouyat, L. E. Band and M. F. Colosimo, "Soil Nitrogen Cycle Processes in Urban Riparian Zones,” Environmental Science \& Technology, Vol. 36, No. 21, 2002, pp. 4547-4552. doi:10.1021/es020649z

[6] J. Dill, "Evaluating a New Urbanist Neighborhood,” Berkeley Planning Journal, Vol. 19, No. 1, 2006, pp. 59-78.

[7] E. Bedan and J. Clausen, “Stormwater Runoff Quality and Quantity from Traditional and Low Impact Development watersheds," Journal of the American Water Resources Association, Vol. 45, No. 4, 2009, pp. 998-1008. doi:10.1111/j.1752-1688.2009.00342.x

[8] C. Pyke, M. Warren, T. Johnson, J. LaGro, J. Scharfenderg, P. Groth, R. Freed, W. Schroeer and E. Main, "Assessment of Low Impact Development for Managing Stormwater with Changing Precipitation Due to Climate Change," Landscape and Urban Planning, Vol. 103, No. 2, 2011, pp. 166-173. doi:10.1016/j.landurbplan.2011.07.006

[9] O. J. Furuseth, "Neotraditional Planning: A New Strategy for Building Neighborhoods?” Land Use Policy, Vol. 14, No. 3, 1997, pp. 201-213. doi:10.1016/S0264-8377(97)00002-1

[10] P. R. Berke, J. MacDonald, N. White, M. Holmes, D. Line, K. Oury and R. Ryznar, "Greening Development to Protect Watersheds: Does New Urbanism make a Difference?” Journal of the American Planning Association, Vol. 69, No. 4, 2003, pp. 397-413. doi:10.1080/01944360308976327

[11] M. E. Dietz, "Low Impact Development Practices: A Review of Current Research and Recommendations for Future Directions," Water, Air, and Soil Pollution, Vol. 186, No. 1-4, 2007, pp. 351-363. doi:10.1007/s11270-007-9484-Z

[12] J. K. Holman-Dodds, A. A. Bradley and K. W. Potter, "Evaluation of Hydrologic Benefits of Infiltration Based Urban Stormwater Management," Journal of the American Water Resources Association, Vol. 39, No. 1, 2003, pp. 205-215. doi:10.1111/j.1752-1688.2003.tb01572.x

[13] M. J. Hood, J. C. Clausen and G. S. Warner, “Comparison of Stormwater Lag Times for Low Impact and Traditional Residential Development," Journal of the American Water Resources Association, Vol. 43, No. 4, 2007, pp. 1036-1046. doi:10.1111/j.1752-1688.2007.00085.x

[14] P. A. Davis, "Green Engineering Principals Promote LowImpact Development," Environmental and Science Technology, Vol. 39, No. 16, 2005, pp. 338A-344A. doi:10.1021/es053327e

[15] D. Burns, T. Vitvar, J. McDonnell, J. Hassett, J. Duncan and C. Kendall, "Effects of Suburban Development on Runoff Generation in the Croton River Basin, New York, USA,” Journal of Hydrology, Vol. 311, No. 1-4, 2005, pp. 266-281. doi:10.1016/j.jhydrol.2005.01.022
[16] S. D. Khan, "Urban Development and Flooding in Houston Texas, Inferences from Remote Sensing Data using Neural Network Technique,” Environmental Geology, Vol. 47, No. 8, 2005, pp. 1120-1127. doi:10.1007/s00254-005-1246-X

[17] Y. P. Lin, Y. B. Lin, Y. T. Wang and N. M. Hong, "Monitoring and Predicting Land-Use Changes and the Hydrology of the Urbanized Paochiao Watershed in Taiwan Using Remote Sensing Data, Urban Growth Models and a Hydrological Model,” Sensors, Vol. 8, No. 2, 2008, pp. 658-680. doi:10.3390/s8020658

[18] S. Suriya and B. V. Mudgal, "Impact of Urbanization on Flooding: The Thirusoolam Sub Watershed-A Case Study," Journal of Hydrology, Vol. 412-413, 2012, pp. 210-219. doi:10.1016/j.jhydrol.2011.05.008

[19] Circle C Ranch, "Circle C Ranch Homeowners Association,” 2012. http://www.circlecranch.info

[20] National Oceanographic and Atmospheric Administration (NOAA), "National Weather Service Forecast Office, Austin/San Antonio, TX,” 2012. http://www.nws.noaa.gov/climate/xmacis.php?wfo=ewx

[21] R. A. Earl and T. Kimmel, "Means and Extremes: The Weather and Climate of South-central Texas," In: J. F. Petersen and J. A. Tuason, Eds., A Geographic Glimpse of Central Texas and the Borderlands, National Council for Geographic Education, Pennsylvania, 1995, pp. 31-40.

[22] US Soil Conservation Service (US SCS), "Soil Survey of Travis County, Texas,” US SCS, Austin, 1974. doi:10.1016/j.jenvman.2006.06.023

[23] C. McColl and G. Aggett, "Land Use Forecasting and Hydrologic Model Integration for Improved Land Use Decision Support,” Journal of Environmental Management, Vol. 84, No. 4, 2007, pp. 494-512.

[24] US Army Corps of Engineers (US ACE), "Hydrologic Modeling System HEC-HMS: Technical Reference Manual,” US ACE, Washington DC, 2000.

[25] Y. Guo and M. Markus, "Analytical Probabilistic Approach for Estimating Design Flood Peaks of Small Watersheds," Journal of Hydrologic Engineering, Vol. 16, No. 11, 2011, pp. 847-857. doi:10.1061/(ASCE)HE.1943-5584.0000380

[26] C. J. Woltemade, "Impact of Residential Soil Disturbance on Infiltration Rate and Stormwater Runoff," Journal of the American Water Resources Association, Vol. 46, No. 4, 2010, pp. 700-711. doi:10.1111/j.1752-1688.2010.00442.x

[27] US Soil Conservation Service (US SCS), "National Engineering Handbook, Section 4, Hydrology,” US SCS, Washington DC, 1972.

[28] W. H. Asquith and M. C. Roussel, "Atlas of Depth-Duration Frequency of Precipitation and Annual Maxima for Texas," Scientific Investigations Report 2004-5041, US Geological Survey, Austin, 2004.

[29] M. R. Knebl, Z. L. Yang, K. Hutchinson and D. R. Maidment, "Regional Scale Flood Modeling Using NEXRAD Rainfall, GIS, and HEC-HMS/RAS: A Case Study for the San Antonio River Basin Summer 2002 Storm Event," Journal of Environmental Management, Vol. 75, No. 4, 2005, pp. 325-336. doi:10.1016/j.jenvman.2004.11.024 